\title{
Caracterização de minério de ouro aluvionar com o uso do concentrador Falcon
}

\author{
Arthur Andrade Ricardo ${ }^{{ }^{*}}$ \\ Rísia Magriotis Papini ${ }^{1}$ (D) \\ Bruno Augusto Cabral Góes ${ }^{2}$
}

\section{Resumo}

A concentração de ouro aluvionar inicia-se utilizando a densidade como propriedade diferenciadora dos minerais na concentração gravítica. Realizou-se a caracterização tecnológica de um minério de ouro aluvionar de um garimpo no estado do Mato Grosso, Brasil, onde o minério aluvionar é alimentado numa calha concentradora e seu rejeito com ouro mais fino é descartado. Sem haver cominuição, as amostras de alimentação (AC) e descarga da calha (DC), classificadas em $1700 \mu \mathrm{m}$, passaram pelo concentrador gravítico Falcon na primeira etapa, seu rejeito foi posteriormente classificado em $837 \mu \mathrm{m}$ para a segunda etapa, a fim de verificar a influência da granulometria na recuperação do ouro com o auxílio de análises granuloquímicas. Com teor de Au inicial de $0,02 \mathrm{~g} / \mathrm{t}$, a amostra DC obteve $3,83 \mathrm{~g} / \mathrm{t}$ após a primeira etapa do Falcon, representando uma recuperação de ouro de $92,5 \%$, enquanto os resultados da amostra AC não foram expressivos, indicando falta de representatividade. Assim, o concentrador Falcon mostrou-se promissor para o tratamento do rejeito da calha, em que foi estimada a possibilidade de recuperar cerca de $11,8 \mathrm{~g} / \mathrm{h}$ de ouro com o equipamento, material usualmente descartado.

Palavras-chave: Concentração gravítica; Minério de ouro; Calha concentradora; Concentrador Falcon.

\section{Characterization of alluvial gold ore using the Falcon concentrator}

\begin{abstract}
Alluvial gold concentration begins by using density as the differentiating property of minerals in gravitic concentration. It was carried out the technological characterization of an alluvial gold ore from an artisanal gold mine in the state of Mato Grosso, Brazil, where alluvial ore is fed in sluice concentrator and its finer gold tailings are discarded. Without comminution, the feeding samples (AC) and discharge of the sluice (DC), classified in $1700 \mu \mathrm{m}$, passed through the Falcon gravitic concentrator in the first stage, whose tailings were subsequently classified at $837 \mu \mathrm{m}$ for the second stage, to verify the influence of particle size on gold recovery with the aid of granulochemical analyses, $\mathrm{x}$-ray diffraction, $\mathrm{x}$-ray fluorescence and fire assay. With an initial Au grade of $0.02 \mathrm{~g} / \mathrm{t}$, the DC sample obtained the best result, reaching $3.83 \mathrm{~g} / \mathrm{t}$ after the first stage of the Falcon, representing a gold recovery of $92.5 \%$, while the results of the AC sample were not very expressive, indicating lack of representativeness. Thus, the Falcon concentrator proved promising for the treatment of tailings from the sluice, where it was estimated the possibility of recovering around $11,8 \mathrm{~g} / \mathrm{h}$ of gold with the equipment, material usually discarded.
\end{abstract}

Keywords: Gravitic concentration; Gold ore; Sluice concentrator; Falcon concentrator.

\section{Introdução}

O Brasil é um país que tem contato com o garimpo desde o seu descobrimento, atividade de extração de substâncias minerais que deve ser regulamentada legalmente com supervisão da Agência Nacional de Mineração (ANM). Atualmente o Código de Mineração Brasileiro regulamenta a atividade garimpeira através de um instrumento conhecido como Permissão de Lavra Garimpeira (PLG) [1], que autoriza a atividade sem pesquisa prévia de minerais garimpáveis, onde o ouro aluvionar é enquadrado. A realidade atual dos depósitos aluvionares em conjunto com as regulamentações

${ }^{1}$ Departamento de Engenharia de Minas - DEMIN, Universidade Federal de Minas Gerais - UFMG, Belo Horizonte, MG, Brasil.

${ }^{2}$ Departamento de Engenharia, Metamat, Companhia Matogrossense de Mineração, Cuiabá, MT, Brasil.

*Autor correspondente: arthur.andrade.ricardo@gmail.com 
ambientais não permite mais que os garimpos legalizados sejam conduzidos de forma arcaica, sem planejamento e utilizando de trabalho braçal para lavra, incentivando a busca por conhecimento técnico-científico para a melhoria contínua e otimização da recuperação do ouro aluvionar que, na medida em que se avança para horizontes mais profundos, fica cada vez mais fino granulometricamente.

A mineralogia destes depósitos permite que seja utilizada a concentração gravítica como forma de concentração do ouro, técnica antiga e rudimentar que procede a faiscação ou cata manual. Quando a propriedade diferenciadora dos minerais presentes no minério é a densidade, como na concentração de ouro aluvionar, utilizam-se equipamentos de concentração gravítica por ação de força da gravidade ou por forças centrífugas, considerando ainda o tamanho e formas destas partículas, como calha, jigue e concentradores centrífugos [2,3], favorecidos ainda por serem menos onerosos e mais ecológicos [4]. Variáveis como o grau de liberação do ouro, o formato das partículas, a porcentagem de sólidos na polpa a ser processada, sua viscosidade e a distribuição granulométrica devem ser consideradas de acordo com o método de concentração gravítica utilizado [5].

O ouro aluvionar é relativamente fácil de encontrar e recuperar utilizando uma tecnologia simples e barata. Usualmente não é necessária a fragmentação ou desmonte com explosivos, nem a necessidade de escavar túneis ou remover grande quantidade de estéril para acessar o minério contendo o ouro [6].

Entre os equipamentos de concentração gravítica, tem-se a calha concentradora, onde a separação é realizada pelo escoamento da polpa sobre uma superfície inclinada a velocidade constante. O processo utiliza apenas a força da gravidade para auxiliar na separação, a qual é baseada na sedimentação de partículas, sendo amplamente difundida ao redor do mundo no tratamento de minérios aluvionares, principalmente em áreas de garimpo, devido ao seu baixo custo de investimento e operação, alta capacidade e recuperação, além da facilidade de operação e instalação. Equipamentos de concentração centrífuga permitem que se trabalhe em faixas de tamanho mais finas, como de $5 \mu \mathrm{m}$ a $6 \mathrm{~mm}$ no concentrador Falcon, além de apresentarem boa efíciência, maiores capacidades e custos de manutenção e operação relativamente baixos $[2,3,7]$.

O concentrador centrífugo Falcon é composto de uma cesta cilíndrico-cônica alinhada verticalmente que gira a alta velocidade no interior do cilindro fixo externo. A polpa é alimentada no fundo do cone em rotação e, devido à sua configuração, as partículas movem-se progressivamente até a parte superior. Durante este movimento, ocorre a diminuição da espessura da camada de partículas, onde as mais leves se soltam pelo movimento rápido do fluxo de água e então retornam à polpa, constituindo o rejeito. As partículas densas ficam retidas na parede interna do cone [3,7]. O Falcon é indicado em casos onde deseja-se recuperar uma pequena fração de material fino e pesado e há um descarte significativo da massa alimentada [8], em que suas variáveis operacionais são a taxa de alimentação, a porcentagem de sólidos na alimentação e a granulometria do minério [7]. Em amostras com granulometria abaixo de $30 \mu \mathrm{m}$, o Falcon pode alcançar uma recuperação de ouro de até $99 \%$ [9].

No presente trabalho foi feita uma caracterização tecnológica de amostras de alimentação (AC) e de descarga (DC) de uma calha concentradora de um garimpo de minério de ouro aluvionar do Mato Grosso, Brasil, para analisar o potencial uso do concentrador Falcon e estimar a quantidade de ouro fino que é descartado pela técnica atual de concentração (calhas).

\section{Metodologia}

No garimpo do norte do Mato Grosso, localizado próximo das cidades de Matupá e Peixoto de Azevedo, onde o cascalho aluvionar tem espessura aproximada de 1 metro e está a uma profundidade de 10 a 12 metros, o decapeamento é feito com o auxílio de trator de esteiras e escavadeiras hidráulicas até a exposição do cascalho aurífero. Com auxílio de monitores hidráulicos, o material desagregado em polpa é então dragado até uma calha concentradora.

Como $85 \%$ da produção deste garimpo vem do cascalho aluvionar, foram coletadas duas amostras para análise: Polpa da alimentação da calha concentradora (Amostra AC) e polpa da descarga da calha concentradora (Amostra DC). Foi proposto um fluxograma de processos (Figura 1) onde a cominuição foi descartada, visto que, por se tratar de ouro

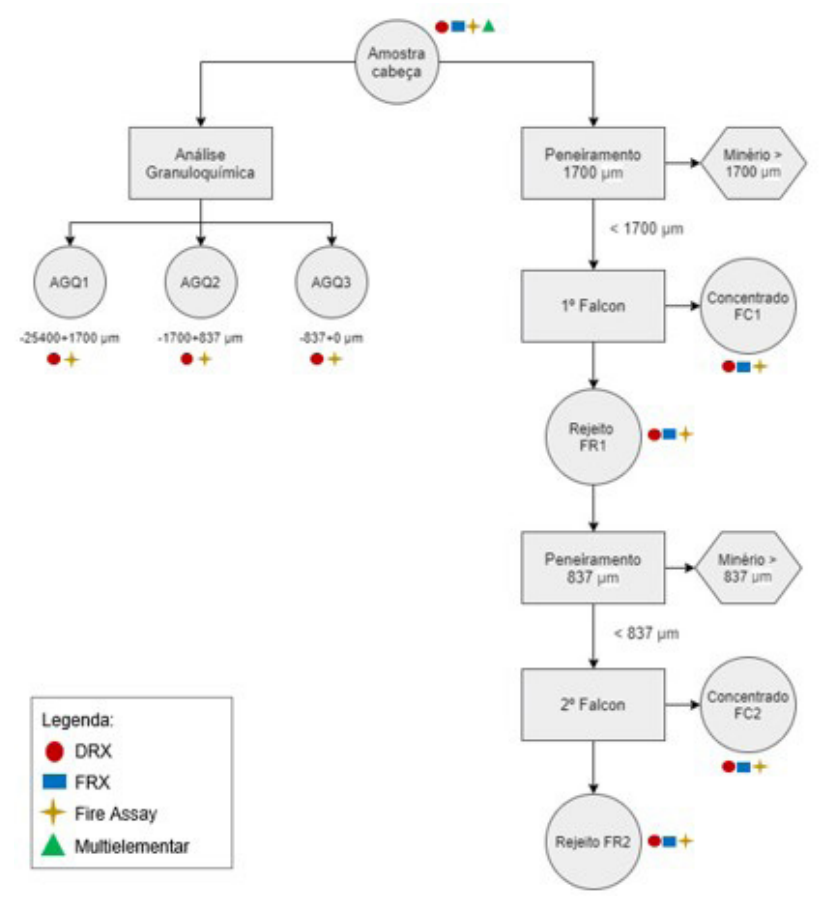

Figura 1. Fluxograma de caracterização e concentração preliminar das amostras AC e DC. 
aluvionar, espera-se que todo o ouro esteja livre, além de ser inviável o uso de moinhos no garimpo.

Foram separadas amostras para a caracterização do material com o objetivo de identificar os minerais presentes através da caracterização das suas estruturas cristalinas por difração de raios-X (DRX - difratômetro PhilipsPanalytical, modelo EMPYREAN, utilizando radiação $\mathrm{CuK} \alpha$ e monocromador), baseando-se na comparação dos valores das distâncias interplanares e das intensidades dos picos nos difratogramas das amostras analisadas e uma amostra de referência, utilizando o padrão do banco de dados PDF-2 Release 2010 do ICDD - International Centre for Diffraction Data e o software X'Pert HighScore PLUS versão 4.0, também utilizado para a quantificação das fases pelo método de Rietveld, o qual faz uso da difração de raios-X para realizar refinamento de célula unitária, refinamento de estrutura cristalina e análise quantitativa de fases. A análise por fluorescência de raios-X(FRX - WDS Philips/Panalytical, modelo PW-2404, tubo com anodo de Rh) permitiu identificar os elementos químicos das amostras (análise qualitativa), assim como quantificar a proporção (concentração) em que cada elemento se encontra nas mesmas.

Para a determinação da densidade real da amostra, utilizou-se o picnômetro como instrumento de medição, realizando a técnica em triplicata para minimizar possíveis erros oriundos de falhas operacionais.

Utilizando a série Tyler de peneiras, foi realizado um peneiramento a úmido para retirar as partículas finas que poderiam estar presas nas maiores e posteriormente a seco. Após a pesagem do material retido nas peneiras, cada amostra foi separada em três faixas granulométricas: $-25400+1700 \mu \mathrm{m},-1700+837 \mu \mathrm{m}$ e $-837+0 \mu \mathrm{m}$, as quais são referência para a etapa de concentração.

Devido às restrições operacionais no garimpo, optou-se por fazer a classificação do material por meio do peneiramento a fim de obter a especificação granulométrica limite para a operação do concentrador gravimétrico Falcon, além da importância da classificação, por peneiramento ou hidrociclone, para qualquer tipo de concentração gravítica, o que pode prejudicar a recuperação de ouro no garimpo caso não seja feito [10]. O material passante da primeira peneira de $1700 \mu \mathrm{m}$ seguiu para a primeira etapa no concentrador Falcon, respeitando o seu limite superior para operação em escala laboratorial. Com o auxílio de um alimentador vibratório e com um fluxo de material que não fosse sobrecarregar a operação, as amostras AC e DC foram continuamente molhadas por um jato de água de lavagem na parte superior do Falcon para que não ficassem acumuladas ou presas. O concentrador operou com $55,3 \mathrm{~Hz}$ de vibração, taxa de $5 \mathrm{~L} / \mathrm{min}$ de água de lavagem interna e modo de operação "Prog5"; parâmetros verificados no manual do equipamento. O rejeito, após secagem, continuou o processo e, para verificar a influência da granulometria na recuperação do ouro, passou por uma peneira de $837 \mu \mathrm{m}$, onde o material passante alimentou a segunda etapa no concentrador Falcon utilizando os mesmos parâmetros operacionais da primeira etapa, finalizando o processo. Os concentrados e rejeitos das duas etapas no concentrador Falcon foram pesados, quarteados e levados para análise química e mineralógica (DRX, FRX e fire assay - por espectroscopia de absorção atômica) a fỉm de avaliar recuperações mássica e de ouro.

\section{Resultados}

Testes de DRX indicaram que as amostras iniciais são compostas predominantemente de quartzo e uma porcentagem menor de feldspatos (Figura 2), enquanto o FRX, quantificado na forma de óxidos, indicou uma média de $90,63 \%$ de $\mathrm{SiO}_{2}, 4,05 \%$ de $\mathrm{Al}_{2} \mathrm{O}_{3}$, menos de $2 \%$ de $\mathrm{Fe}_{2} \mathrm{O}_{3}$ e porcentagens muito pequenas de outros óxidos $\left(\mathrm{K}_{2} \mathrm{O}, \mathrm{CaO}\right.$, $\mathrm{TiO}_{2}, \mathrm{Cr}_{2} \mathrm{O}_{3}, \mathrm{MnO}, \mathrm{P}_{2} \mathrm{O}_{5}, \mathrm{MgO}$ e $\mathrm{Na}_{2} \mathrm{O}$ ).

Analisando as curvas granulométricas das amostras AC e DC (Figura 3), percebe-se que o D80 da amostra DC (cerca de $2900 \mu \mathrm{m}$ ) é maior que o da AC (cerca de $2400 \mu \mathrm{m}$ ), mas não há uma diferença de tamanho muito marcante entre as amostras abaixo de $1200 \mu \mathrm{m}$.

Para a determinação da densidade real da amostra $\mathrm{AC}$, a qual não passou por nenhum método de concentração,

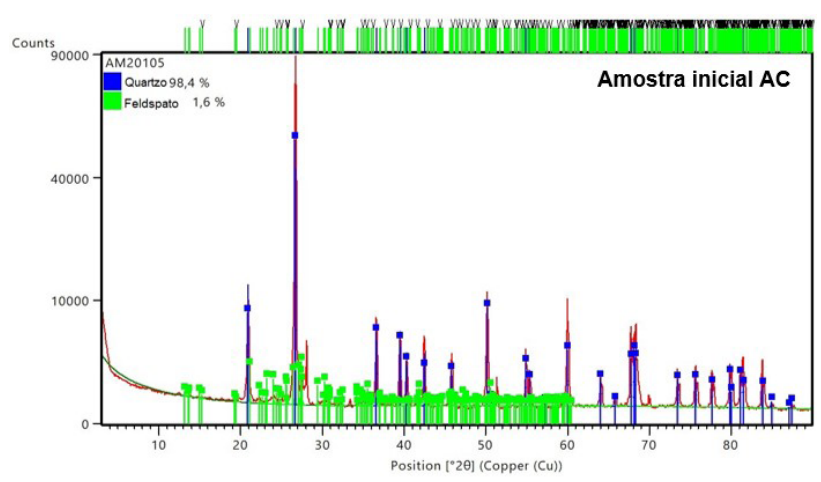

Figura 2. Difratograma da amostra inicial AC, semelhante ao da amostra DC.

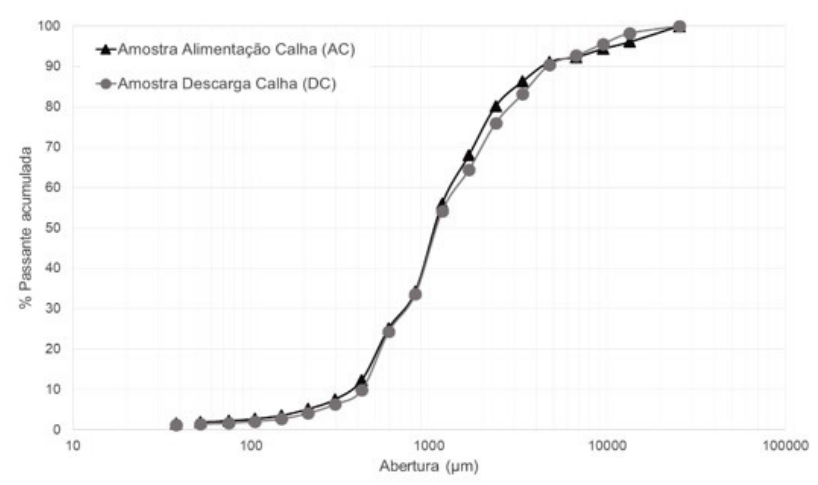

Figura 3. Curvas granulométricas das amostras AC e DC. 
realizou-se o teste de picnometria em triplicata, onde o resultado encontra-se na Tabela 1. Este resultado auxiliará no cálculo da porcentagem de sólidos na polpa que alimenta a calha concentradora.

Por meio dos testes de fire assay, obteve-se teor de ouro de 0,01 e 0,02 g/t para as amostras iniciais AC e DC, respectivamente. Após a primeira classificação na peneira de $1700 \mu \mathrm{m}$, em que a massa passante corresponde a mais de $60 \%$ do total, o teor alimentado no Falcon foi alterado, o qual foi calculado por meio das massas e teores de ouro do concentrado e rejeito, resultado apresentado na Tabela 2, onde contém o balanço de massa dos processos, e, na Figura 4, as recuperações mássica e de ouro das amostras.

Foi feita então uma estimativa da quantidade de ouro perdida na descarga da calha concentradora baseado nos resultados obtidos na primeira etapa do Falcon da amostra DC e dados do garimpo em estudo, como a taxa de alimentação da calha, a densidade da polpa e a recuperação mássica (Tabela 3 ).

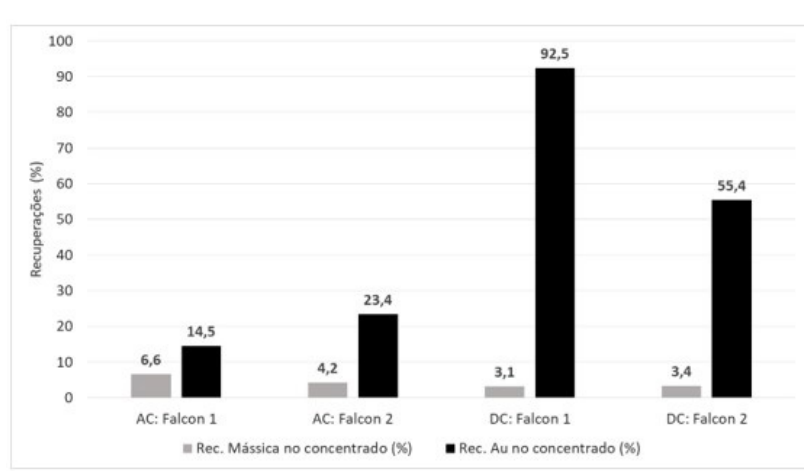

Figura 4. Recuperações mássica e de ouro das amostras AC e DC.

Tabela 1. Densidade real da amostra AC por picnometria

\begin{tabular}{cc}
\hline Picnômetro & Densidade $\left(\mathbf{g} / \mathbf{c m}^{3}\right)$ \\
\hline 1 & 2,527 \\
2 & 2,611 \\
3 & 2,649 \\
Média & 2,596 \\
\hline
\end{tabular}

Assim, foi estimado que $11,8 \mathrm{~g} / \mathrm{h}$ de ouro descartado pela calha poderia ser recuperado pelo Falcon. De acordo com o regime de operação do garimpo, o qual pode variar de 8 até 12 horas por dia, estimou-se o valor da venda deste ouro em um ano, considerando a cotação do dia 16 de julho de 2020 (Tabela 4).

No cenário com 8 horas de trabalho por dia, seria esperado um retorno financeiro de cerca de 2 milhões de dólares ao garimpo, valor muito além do investimento necessário para se obter um concentrador Falcon.

\section{Discussão}

É perceptível que os resultados mais expressivos, principalmente na primeira etapa do Falcon, foram os da amostra DC (Tabela 5), material mais fino inicialmente descartado pelo garimpo. Tal resultado evidencia o uso deste tipo de concentrador centrífugo para amostras onde deseja-se recuperar uma pequena fração de material fino e pesado com um descarte significativo da massa alimentada, onde há uma pequena recuperação mássica.

Estes resultados corroboram a origem do ouro no local, associado a veios de quartzo que, ao sofrerem ações do intemperismo, desprenderam-se da rocha original e foram transportados pela ação dos ventos e rios, formando os aluviões. Além disso, vê-se que, mesmo possuindo curvas granulométricas parecidas abaixo de $1700 \mu \mathrm{m}$, a amostra $\mathrm{DC}$ tem maior quantidade de ouro em relação à amostra $\mathrm{AC}$ nesta faixa de tamanho, comprovado pelo teste fire assay.

Dessa forma, os dados retornam que existe uma grande influência na classificação granulométrica prévia à concentração gravítica. A inclusão de uma etapa de classificação e posterior concentração gravítica, seja com a utilização de calhas simples ou concentradores centrífugos, por faixa de tamanho pode resultar em ganhos na recuperação. No entanto, para uma afirmação definitiva sobre a influência granulométrica na recuperação gravimétrica no sentido de uma proposição de novos circuitos de concentração, será necessária uma análise com amostras de maior volume de forma a ter maior representatividade.

Tabela 2. Balanço de massa das etapas no Falcon das amostras AC e DC

\begin{tabular}{|c|c|c|c|c|c|c|c|c|}
\hline \multirow[b]{2}{*}{ Amostra } & \multicolumn{4}{|c|}{ Falcon 1} & \multicolumn{4}{|c|}{ Falcon 2} \\
\hline & $\begin{array}{c}\text { Massa } \\
\text { (g) }\end{array}$ & $\begin{array}{c}\text { Teor Au } \\
(\mathrm{g} / \mathrm{t})\end{array}$ & $\begin{array}{c}\text { Rec. Mass. } \\
(\%)\end{array}$ & $\begin{array}{c}\text { Rec. Au } \\
(\%)\end{array}$ & $\begin{array}{c}\text { Massa } \\
\text { (g) }\end{array}$ & $\begin{array}{c}\text { Teor Au } \\
(\mathrm{g} / \mathrm{t})\end{array}$ & $\begin{array}{c}\text { Rec. Mass. } \\
(\%)\end{array}$ & $\begin{array}{c}\text { Rec. Au } \\
(\%)\end{array}$ \\
\hline Alimentação AC* & 4352,7 & 0,055 & 100 & 100 & 2147,7 & 0,013 & 100 & 100 \\
\hline Concentrado AC & 287,2 & 0,12 & 6,6 & 14,5 & 89,6 & 0,07 & 4,2 & 23,4 \\
\hline Rejeito AC & 4065,5 & 0,05 & 93,4 & 85,5 & 2058,1 & 0,01 & 95,8 & 76,6 \\
\hline Alimentação DC* & 4746,9 & 0,128 & 100 & 100 & 2711,2 & 0,065 & 100 & 100 \\
\hline Concentrado DC & 147,2 & 3,83 & 3,1 & 92,5 & 91,4 & 1,07 & 3,4 & 55,4 \\
\hline Rejeito DC & 4599,7 & 0,01 & 96,9 & 7,5 & 2619,8 & 0,03 & 96,6 & 44,6 \\
\hline
\end{tabular}

*Alimentação recalculada. 
Tabela 3. Estimativa da quantidade de ouro perdida na descarga da calha concentradora com o auxílio de resultados obtidos no Falcon

\begin{tabular}{|c|c|c|}
\hline Dados & Valor & Unidade \\
\hline Taxa de alimentação da calha concentradora & 350 & $\mathrm{~m}^{3} / \mathrm{h}$ \\
\hline Densidade da polpa & 1,279 & $\mathrm{t} / \mathrm{m}^{3}$ \\
\hline Massa da polpa de alimentação da calha concentradora & 447,7 & $\mathrm{t} / \mathrm{h}$ \\
\hline Densidade do minério & 2,596 & $\mathrm{t} / \mathrm{m}^{3}$ \\
\hline \% Sólidos da polpa & 35,5 & $\%$ \\
\hline Massa de alimentação da calha concentradora & 158,8 & $\mathrm{t} / \mathrm{h}$ \\
\hline Recuperação mássica estimada da calha concentradora* & 2 & $\%$ \\
\hline Massa de descarga da calha concentradora (Alimentação da peneira pré-Falcon) & 155,7 & $\mathrm{t} / \mathrm{h}$ \\
\hline$\%$ Passante na peneira pré-Falcon $(<1700 \mu \mathrm{m})$ & 63,7 & $\%$ \\
\hline Massa de alimentação $1^{\text {a }}$ Etapa Falcon & 99,2 & $\mathrm{t} / \mathrm{h}$ \\
\hline Recuperação mássica $1^{\mathrm{a}}$ Etapa Falcon & 3,10 & $\%$ \\
\hline Massa de concentrado $1^{\text {a }}$ Etapa Falcon & 3,07 & $\mathrm{t} / \mathrm{h}$ \\
\hline Teor de Au do concentrado $1^{\text {a }}$ Etapa Falcon & 3,8 & $\mathrm{~g} / \mathrm{t}$ \\
\hline Quantidade de ouro no concentrado $1^{\text {a }}$ Etapa Falcon & 11,8 & $\mathrm{~g} / \mathrm{h}$ \\
\hline
\end{tabular}

*Estimativa considerando parâmetros observados na visita ao garimpo.

Tabela 4. Estimativa da quantidade de ouro perdida por ano e seu valor de venda

\begin{tabular}{ccccc}
\hline $\begin{array}{c}\text { Cenários: Horas de } \\
\text { operação no garimpo } \\
\text { por dia }\end{array}$ & $\begin{array}{c}\text { Massa de ouro } \\
\text { (g/dia) }\end{array}$ & $\begin{array}{c}\text { Massa de ouro } \\
(\mathbf{g} / \mathbf{m e ̂ s})\end{array}$ & $\begin{array}{c}\text { Massa de ouro } \\
\text { (kg/ano) }\end{array}$ & $\begin{array}{c}\text { Venda do ouro } \\
\text { (USD/ano)* }\end{array}$ \\
\hline $8 \mathrm{~h}$ & 94,2 & 2825,5 & 33,9 & $\$ 1.959 .383,10$ \\
$9 \mathrm{~h}$ & 106,0 & 3178,7 & 38,1 & $\$ 2.204 .305,99$ \\
$10 \mathrm{~h}$ & 117,7 & 3531,9 & 42,4 & $\$ 2.449 .228,87$ \\
$11 \mathrm{~h}$ & 129,5 & 3885,1 & 46,6 & $\$ 2.694 .151,76$ \\
$12 \mathrm{~h}$ & 141,3 & 4238,3 & 50,9 & $\$ 2.939 .074,65$ \\
\hline
\end{tabular}

*Considerando cotação do ouro de 16/07/20: 1797,42 USD/ozt; 1 ozt = 31,10 g.

Tabela 5. Compilado dos resultados da $1^{\text {a }}$ etapa do concentrador Falcon

\begin{tabular}{cccc}
\hline $\mathbf{1}^{\mathbf{a}}$ Etapa Falcon & $\begin{array}{c}\text { Teor de Au no concentrado } \\
(\mathbf{g} / \mathbf{t})\end{array}$ & $\begin{array}{c}\text { Recuperação de ouro no } \\
\text { concentrado }\end{array}$ & $\begin{array}{c}\text { Recuperação mássica no } \\
\text { concentrado }\end{array}$ \\
\hline Amostra AC & 0,12 & $14,50 \%$ & $6,60 \%$ \\
Amostra DC & 3,83 & $92,50 \%$ & $3,10 \%$ \\
\hline
\end{tabular}

\section{Conclusão}

Por meio da caracterização tecnológica das amostras de minério de ouro aluvionar de um garimpo do Mato Grosso, Brasil, e posterior concentração gravítica utilizando o concentrador centrífugo Falcon, foi possível verificar o potencial uso do equipamento. As amostras são compostas predominantemente por quartzo, seguida de feldspatos e outros óxidos, entretanto numa quantidade pequena, como $\mathrm{K}_{2} \mathrm{O}, \mathrm{CaO}, \mathrm{TiO}_{2}, \mathrm{Cr}_{2} \mathrm{O}_{3}, \mathrm{MnO}, \mathrm{P}_{2} \mathrm{O}_{5}, \mathrm{MgO}$ e $\mathrm{Na}_{2} \mathrm{O}$.

A amostra de alimentação da calha concentradora (AC) tinha $0,01 \mathrm{~g} / \mathrm{t}$ de Au e, na primeira etapa, obteve-se um teor de $0,12 \mathrm{~g} / \mathrm{t}$ no concentrado $(14,5 \%$ de recuperação metalúrgica do ouro), enquanto na etapa seguinte alimentada pelo rejeito do primeiro Falcon peneirado em $837 \mu \mathrm{m}$, obteve-se $0,07 \mathrm{~g} / \mathrm{t}$ (23,4\% de recuperação metalúrgica do ouro).

$\mathrm{Na}$ amostra $\mathrm{AC}$, o uso do Falcon não foi tão efetivo, o que não era esperado, visto que era um material que não havia passado por nenhuma etapa de concentração. Suspeita-se que a amostra coletada não tenha sido representativa, necessitando então de uma nova amostragem deste material in loco.

A amostra descarga da calha (DC) tinha teor de ouro de $0,02 \mathrm{~g} / \mathrm{t}$ e obteve teores de $3,83 \mathrm{~g} / \mathrm{t}$ ( $92,5 \%$ de recuperação metalúrgica do ouro) e $1,07 \mathrm{~g} / \mathrm{t}(55,4 \%$ de recuperação metalúrgica do ouro) na primeira e segunda etapa do processo, respectivamente, seguindo a mesma metodologia da amostra AC.

Para a amostra DC, material que é descartado, justifica-se o uso do equipamento Falcon, pois o mesmo recuperou o ouro mais fino que estava sendo perdido no rejeito da calha.

Ao estimar a quantidade de ouro descartada na descarga da calha concentradora, viu-se que cerca de $11,8 \mathrm{~g} / \mathrm{h}$ poderiam ser recuperados no processo e, simulando operações de 8 até $12 \mathrm{~h}$ por dia, esta quantidade de ouro poderia gerar em torno de 2 até 3 milhões de dólares por ano, o que varia, visto que o preço de venda do ouro não é constante, apresentando oscilações. 
Assim, o concentrador gravítico Falcon mostrou-se promissor para o tratamento do rejeito da calha concentradora, podendo trazer uma nova opção de retorno financeiro ao garimpo, além de acompanhar as novas tecnologias que surgem, deixando de lado a ideia de que garimpos atuam apenas de forma ilegal e sem estudos dos processos realizados.

\section{Agradecimentos}

Os autores agradecem ao Departamento de Engenharia de Minas da UFMG, Metamat - Companhia Matogrossense de Mineração pelo apoio logístico na coleta de amostras e à COOGAVEPE - Cooperativa dos Garimpeiros do Vale do Rio Peixoto pelo financiamento do trabalho.

\section{Referências}

1 Brasil. Lei no 7.805, de 18 de julho de 1989. Altera o Decreto-Lei no 227, de 28 de fevereiro de 1967, cria o regime de permissão de lavra garimpeira, extingue o regime de matrícula, e dá outras providências. Diário Oficial da União: seção 1, Brasília, DF, 20 jul. 1989.

2 Lins FAF. Tratamento de minérios. 5. ed. Rio de Janeiro: CETEM/MCT; 2010. Concentração gravítica; p. 301-326.

3 Sampaio CH, Tavares LMM. Beneficiamento gravimétrico: uma introdução aos processos de concentração mineral e reciclagem de materiais por densidade. Porto Alegre: Editora da UFRGS; 2005.

4 Abdel-Khalek NA, El-Shatoury EH, Abdel-Motelib A, Hassan MS, Abdel-Khalek MA, El-Sayed S. Mineralogical study and enhanced gravity separation of gold-bearing mineral, South Eastern Desert, Egypt. Physicochemical Problems of Mineral Processing. 2020;56:839-848.

5 Martinez G, Restrepo-Baena OJ, Veiga MM. The myth of gravity concentration to eliminate mercury use in artisanal gold mining. The Extractive Industries and Society. 2021;8(1):477-485.

6 Teschner B, Smith NM, Borillo-Hunter T, John ZQ, Wong TE. How efficient are they really? A simple testing method of small-scale gold miners' gravity separation systems. Minerals Engineering. 2017;105:44-51.

7 Carriso RCC, Chaves AP. Mecanismos atuantes na concentração gravítica e principais equipamentos utilizados na concentração centrífuga. Rio de Janeiro, CETEM/MCT; 2001.

8 Silva EC, Torres VV, Santos NA. Concentradores centrífugos - uma nova era na concentração gravítica. In: Associação Brasileira de Metalurgia e Materiais. XVII Encontro Nacional de Tratamento de Minérios e Metalurgia Extrativa; São Paulo, Brasil; São Pedro: ABM; 1998. p. 533-551.

9 Ernawati R, Idrus A, Petrus HTBM. Study of the optimization of gold ore concentration using gravity separator (shaking table): case study for LS epithermal gold deposit in Artisinal Small scale Gold Mining (ASGM) Paningkaban, Banyumas. In: IOP Conferences. International Conference on Earth Science, Mineral, and Energy; 2018 11-12 October 2018; Yogyakarta, Indonesia. Central Java: IOP Conference Series: Earth and Environmental Science.

10 Veiga MM, Gunson AJ. Gravity concentration in artisinal gold mining. Minerals. 2020;10(11):1026.

Recebido em: 24 Nov. 2020

Aceito em: 5 Mar. 2021 